\title{
Rationale for Implementation of Warm Cardiac Surgery in Pediatrics
}

\author{
Yves Durandy ${ }^{1,2 *}$ \\ ${ }^{1}$ Perfusion Department, CCML, Le Plessis Robinson, France, ${ }^{2}$ Intensive Care Department, CCML, Le Plessis Robinson, \\ France
}

Cardiac surgery was developed thanks to the introduction of hypothermia and cardiopulmonary bypass in the early 1950s. The deep hypothermia protective effect has been essential to circulatory arrest complex cases repair. During the early times of open-heart surgery, a major concern was to decrease mortality and to improve short-term outcomes. Both mortality and morbidity dramatically decreased over a few decades. As a consequence, the drawbacks of deep hypothermia, with or without circulatory arrest, became more and more apparent. The limitation of hypothermia was particularly evident for the brain and regional perfusion was introduced as a response to this problem. Despite a gain in popularity, the results of regional perfusion were not fully convincing. In the 1990s, warm surgery was introduced in adults and proved to be safe and reliable. This option eliminates the deleterious effect of ischemia-reperfusion injuries through a continuous, systemic coronary perfusion with

OPEN ACCESS

Edited by:

Oswin Grollmuss,

University Paris Sud, France

Reviewed by:

Yasuhiro Fujii,

Okayama University Hospital,

Japan

Aida Salameh,

Heart Centre University of

Leipzig, Germany

${ }^{*}$ Correspondence:

Yves Durandy

yves.durandy@gmail.com

Specialty section:

This article was submitted to Pediatric Cardiology, a section of the journal

Frontiers in Pediatrics

Received: 30 March 2016 Accepted: 21 April 2016

Published: 06 May 2016

Citation:

Durandy Y (2016) Rationale for Implementation of Warm Cardiac

Surgery in Pediatrics.

Front. Pediatr. 4:43.

doi: 10.3389/fped.2016.00043 warm oxygenated blood. Intermittent warm blood cardioplegia was introduced later, with impressive results. We were convinced by the easiness, safety, and efficiency of warm surgery and shifted to warm pediatric surgery in a two-step program. This article outlines the limitations of hypothermic protection and the basic reasons that led us to implement pediatric warm surgery. After tens of thousands of cases performed across several centers, this reproducible technique proved a valuable alternative to hypothermic surgery.

\section{Keywords: cardiopulmonary bypass, warm perfusion, warm blood cardioplegia, microplegia, pediatric cardiac} surgery

\section{INTRODUCTION}

Perfusion is a typical case of experience-based medicine, and there is no agreement on even such basic factors as priming volume and composition, temperature on bypass, type of cardioplegia and re-dosing intervals, non-pulsatile or pulsatile perfusion. The dogma on the imperative need for hypothermic protection in pediatric cardiac surgery should be discussed in the light of modern anesthesia cardiac surgery and recent cardiopulmonary bypass components. This article aims to present the limitations of hypothermic perfusion and the reasons that led us to implement warm pediatric cardiac surgery.

\section{EVOLUTION OF THE DOGMA ON HYPOTHERMIA PROTECTIVE EFFECT DURING CARDIAC SURGERY}

In the 1950s, two major breakthroughs led to the initiation and development of open-heart surgery: systemic hypothermia and cardiopulmonary bypass. In 1950, Bigelow introduced systemic 
hypothermia with the goal of lowering oxygen requirements, allowing organs exclusion from the circulation for the period necessary for surgery $(1,2)$. Systemic hypothermia was the only way to obtain a bloodless operating field, allowing intracardiac repair under direct vision. In 1952, Lewis first applied systemic hypothermia $\left(28^{\circ} \mathrm{C}\right)$ and a $5.5 \mathrm{~min}$ inflow occlusion to close an atrial septal defect. At the same time, the technology of extracorporeal circulation reached the stage of clinical application, and in 1953, Gibbon used the Gibbon-IBM heart-lung machine to close an atrial septal defect. This was the first open-heart surgery with cardiopulmonary bypass. Initially, the two techniques were used separately. In the 1960 s, topical hypothermia around $28-29^{\circ} \mathrm{C}$ with circulatory arrest was mainly used in Novosibirsk in the treatment of ventricular septal defect, atrioventricular canal, and tetralogy of Fallot (3), while cardiopulmonary bypass with normothermia was mainly used in North America $(4,5)$.

The two innovations were soon combined, and the alteration in systemic temperature was simplified by the addition of a heat exchanger on the bypass circuit (6). Systemic hypothermia was enhanced by topical hypothermia for myocardial protection (7), and by cold cardioplegia in the 1970s $(8,9)$. There was no real consensus on the optimal temperature needed for the treatment of simple and complex cardiopathies. Moderate hypothermia $\left(30^{\circ} \mathrm{C}\right)$ was used very successfully in 337 patients with tetralogy of Fallot (10), but more severe hypothermia was regarded as superior for organs protection allowing an optimal safety margin. Deep hypothermia with circulatory arrest was introduced in the 1960s and later popularized in complex pediatric cases (11-14).

It was commonly admitted that the benefits of hypothermia outweighed its drawbacks, and brain protection during circulatory arrest was indeed a major concern.

The physiology of brain is unique: while this organ accounts for about $2 \%$ of the body weight, its blood flow is $13 \%$ of the cardiac output, and its oxygen consumption is $20 \%$ of the total body oxygen consumption at rest (15). There is no doubt that hypothermia decreases brain oxygen consumption, and it is commonly admitted that this decrease is $6-7 \%$ for every degree below $37^{\circ} \mathrm{C}$. Consequently, safe periods of circulatory arrest were estimated, but without agreement on the predicted safe duration. From one study to another, it varied from 40 to $60 \mathrm{~min}$ for systemic temperature of $20-22^{\circ} \mathrm{C}$, to $29 \mathrm{~min}$ at $15^{\circ} \mathrm{C}$ (16-18). This lack of precision was made even worse by the inconsistency of temperatures recorded at various sites. In a study using electroencephalogram assessment of electrocerebral silence as an objective measure of brain function, the authors demonstrated that temperatures from nasopharynx, esophagus, and rectum were inaccurate in predicting the cessation of brain electrical activity. Electrocerebral silence was observed with nasopharyngeal temperatures varying from 10.1 to $24.1^{\circ} \mathrm{C}$ and rectal temperatures varying from 12.8 to $28.6^{\circ} \mathrm{C}$ (19). The safe duration of circulatory arrest is not the only uncertainty in the management of deep hypothermia and the choice between $\mathrm{pH}$ stat versus $\alpha$-stat strategy is an endless debate (20-26). In the past, despite hypothermic brain protection, neurologic complications were frequent. Postpump chorea was strongly associated with deep hypothermia and circulatory arrest and the prognosis was guarded $(27,28)$. Much more frequent were post circulatory arrest clinical seizures, with an incidence of around 6-10\% $(29,30)$ but three times more when seizures were diagnosed via continuous electroencephalographic monitoring (31). There is some evidence that neonatal seizures are a good surrogate marker of long-term neurologic outcome (32). As survival rate improved for congenital heart surgery, long-term neurodevelopment delays were observed in patients treated with deep hypothermia. The dogma of brain hypothermic protection during circulatory arrest became progressively discussed, and antegrade selective cerebral perfusion was introduced to overcome the side effects of circulatory arrest with profound body hypothermia (33-35). The term cerebroplegia was used for cerebral perfusion with $6-10^{\circ} \mathrm{C}$ blood, while the body was perfused with moderate systemic cooling of around $26^{\circ} \mathrm{C}$. Pediatric surgeons accepted to implement this technique for hypoplastic left heart syndrome first stage palliation or aortic arch surgery $(36,37)$. The benefits were disappointing compared to circulatory arrest, and several works failed to find any positive effect of antegrade cerebral perfusion (38-41). The appropriate hypothermic brain perfusion rate and pressure for neonates remain unknown. Many studies assessed hypothermic perfusion using oxygen delivery or oxygen saturation as a marker of perfusion quality. In fact, high oxygen saturation during hypothermic perfusion may indicate impaired oxygen transfer from blood to tissue rather than normal or over-perfusion (42). Besides, optimizing oxygenation does not mean "the more, the better," and any excessive blood flow can be detrimental, carrying the risk of cerebral edema and intracranial hemorrhage (43).

The mechanisms of hypothermic brain protection are still to be elucidated and decades after its implementation, the management of patients during hypothermia and rewarming is far from uniform. This is, at least in part, due to the lack of clear evidence about the optimal management.

The physiology of the heart is quite unique too. Being a muscle, its myocardial oxygen consumption is mainly related to its activity. At rest, the coronary blood flow represents $5 \%$ of cardiac output, while its oxygen consumption is $11 \%$ of the total consumption (15). Hypothermic myocardial protection during cardiac surgery is more questionable, as hypothermia increases oxygen consumption per beat, the decrease in oxygen consumption observed being due to bradycardia. It has been estimated that myocardial oxygen consumption, normalized for heart rate, more than doubles when temperature decreases from 37 to $22^{\circ} \mathrm{C}$ $(44,45)$. Furthermore, the decrease of myocardial oxygen consumption of an arrested heart is little influenced by temperature and, in dogs, there is an overlapping between myocardial oxygen consumption of a normothermic contracting empty heart and a heart during hypothermic $\left(11^{\circ} \mathrm{C}\right)$ arrest (46).

Hypothermic protection of other organs including kidney, liver, gut, lungs, muscle, skin, and endocrine glands is even more questionable. Hypothermia depresses renal blood flow, glomerular filtration, osmolar clearance, and maximum tubular excretory capacity $(47,48)$. Glomerular filtration rate and renal plasma flow decrease by $40 \%$ at $32^{\circ} \mathrm{C}$ and $70 \%$ at $27^{\circ} \mathrm{C}(49)$. The blood flow of liver, gut, and pancreas is reduced during hypothermia, with a decrease in liver metabolic and excretory functions. There is some concern about the role of hypothermia in the increase in gut permeability and loss of mucosal integrity observed 
following cardiopulmonary bypass. These gastrointestinal changes underline the risk of endotoxin or bacteria translocation from the gut to the blood $(50,51)$. The mechanical effects of hypothermia on lungs have been studied in sheep. A significant decrease in compliance was observed in animals subjected to hypothermia, while compliance was stable in animals subjected to anesthesia alone or normothermic bypass (52). The effects on soft tissue were rapidly established, as the first case of lethal subcutaneous fat necrosis was published in 1953 in a four-anda-half-month-old boy operated on for a tetralogy of Fallot (53). A few cases of this rare complication have been published with a more favorable evolution (54). Endocrine function is altered during hypothermia, the most frequent manifestation being a decrease in insulin production with hyperglycemia (55).

Apart from organ dysfunction, reversible platelet dysfunction (56), depressed immune system (57), and $\mathrm{pH}$ and $\mathrm{PCO}_{2}$ modifications (58) have been related to hypothermia. There is also reasonable suspicion that increased endothelial permeability and edema may contribute to organ malperfusion during cooling and rewarming $(59,60)$.

The side effects of hypothermia are all reversible, and there is no doubt that hypothermic perfusion has been essential to the development and success of cardiac surgery. However, following hypothermia, the delay between normalization of temperature and normalization of organ function and metabolic drawbacks is likely to vary from one case to the other. This is particularly true for neurologic impairment, which may even persist in grown-up children (61), but possibly also for immune function, contributing to a higher risk of postoperative infection (62), and coagulation impairment, with its consequences (bleeding and transfusion) carrying their own risk $(63,64)$.

\section{BRAIN WARM ISCHEMIA: A MISUNDERSTOOD RISK}

A common opinion is that during normothermic, 5- to 10-min circulatory arrest, brain changes and neuronal death are irreversible. This is not totally in agreement with the observations in dogs, which can stand up to $30 \mathrm{~min}$ of circulatory arrest without permanent brain damage, provided blood is removed from the brain before the arrest (65), nor with observations made on humans following prolonged circulatory arrest. In such cases, hypoxia should affect all the brain with symmetrical destruction while, in fact, the destruction of large areas on one side co-occurs with unaffected corresponding areas on the opposite side (65). This is not in agreement with a recent experimental work on pigs, demonstrating that brain recovery following 30-min warm ischemia depends on the quality of reperfusion. The poorest outcomes, including brain edema and extensive cerebral infarct, were observed with "uncontrolled reperfusion," while pulsatile "controlled reperfusion" resulted in minimal brain edema and no brain infarction. Uncontrolled reperfusion was defined as normal blood reperfusion by the pig heart, and controlled perfusion was performed via a mechanical pump with a high flow (66). This experimental work could contribute to explain the superior results observed with extracorporeal membrane oxygenation rescue versus conventional cardiopulmonary resuscitation. In one work on in-hospital cardiac arrest in pediatric patients, 11/27 patients (41\%) were survivors, 10 of them having good neurologic outcomes (67).

There is, of course, no study establishing the safe limit of brain warm ischemia in man, and data have only been gathered from experience. Unexpected recoveries were observed following treatment of massive hemorrhage with deliberate circulatory arrest using induced ventricular fibrillation. Normothermic arrests up to $14 \mathrm{~min}$ were observed without sequelae (68). There is some evidence that the time to irreversible brain damage following normothermic brain ischemia is not necessarily as short as commonly admitted. Ischemia-reperfusion effects could be influenced by the quality of reperfusion and anticoagulation avoiding thrombosis in small brain vessels during circulatory arrest.

During full flow warm oxygenated blood perfusion, brain perfusion is controlled by auto-regulation. In case of an incident requiring circulatory arrest longer than the "classical" safe limit, controlled reperfusion should be used to obtain full recovery of the neurologic function. The new challenge is therefore to compare the inherent risks of hypothermic brain perfusion or hypothermic circulatory arrest against the inherent risks of warm perfusion.

\section{WARM CARDIAC SURGERY, THE ADULT EXPERIENCE}

Continuous whole body warm perfusion with oxygenated blood is one way to avoid the deleterious effects related to ischemiareperfusion. This option, used in the early years of cardiac surgery $(4,5)$, was then abandoned until 1989 , when a 64 -year-old woman was operated on for mitral valve surgery with $33^{\circ} \mathrm{C}$ perfusion and $37^{\circ} \mathrm{C}$ continuous cardioplegia infusion. Due to cardiac rupture, the cross clamp time was $393 \mathrm{~min}$. This patient was easily weaned off bypass without inotropic support or intra-aortic balloon pump, but died $17 \mathrm{~h}$ later from recurrence of arterio-ventricular separation (69). Following this impressive result, a randomized study on 1,732 coronary bypass surgery patients, classified into warm group $(n=860)$ and cold group $(n=872)$, failed to demonstrate any advantage of hypothermic brain protection, and serial creatine kinase MB fraction levels were significantly lower in the warm group $(70,71)$.

The constraint imposed by continuous cardioplegia infusion, be it antegrade or retrograde, was overcome in 1995. Intermittent antegrade warm blood was compared to cold blood cardioplegia in two groups of coronary artery bypass graft patients. The warm group showed improved outcomes in term of immediate hemodynamics and peak concentration of creatine kinase myocardialspecific isoenzyme. The incidence of myocardial infarction and stroke was lower in the warm group, albeit not reaching significance $(72,73)$. Warm perfusion and intermittent warm blood cardioplegia was implemented by other groups, confirming the feasibility, safety, and benefits of the technique (74-77). A metaanalysis failed to demonstrate any difference related to perfusion temperature in the incidence of stroke and deterioration of the 
neuropsychological function following cardiopulmonary bypass (78). The lack of difference between cold and warm perfusion could be due to the fact that the period at higher risk of embolization occurred at the beginning and the end of bypass, when patients of both groups were normothermic. It is noteworthy that warm adult surgery, introduced 20 years ago, is used worldwide and that the risk of bypass circuit mechanical incident-related brain ischemia is more than exceptional. Intermittent warm blood cardioplegia was mainly used in coronary artery bypass graft and re-dosing intervals of $15 \mathrm{~min}$ or less were more than sufficient to perform a distal anastomosis. However, there was some concern regarding the maximum safe time to re-dosing. In the literature, the safe time to re-dosing increases progressively with increased experience in warm surgery. It was $5 \mathrm{~min}$ in 1992 (79), 10-15 min in 1995 (73-75), $30 \mathrm{~min}$ in 2000 (80), or even more. Single shot warm blood cardioplegia was used for aortic clamp time between 29 and $47 \mathrm{~min}$ (81).

\section{IMPLEMENTATION OF WARM PEDIATRIC SURGERY A TWO-STEP SHIFT}

We found several aspects attractive in warm perfusion and with recent oxygenators circuits and cannula, in experienced hands, the need for circulatory arrest was no longer essential. In the early 1990s, we thus shifted from cold to warm perfusion. Continuous warm blood cardioplegia being unrealistic in pediatric patients, the first step of our protocol combined warm perfusion with cold blood cardioplegia. The prime was heated to $37^{\circ} \mathrm{C}$ and the heater-cooler unit was set to $37.5^{\circ} \mathrm{C}$ during the whole bypass time. Such a protocol was not totally satisfactory, but we learned that warm perfusion was feasible and safe and observed a number of positive outcomes. As expected, time on bypass, a classical risk factor in pediatric cardiac surgery, decreased. The endless debate on the best $\mathrm{pH}$ management during hypothermic perfusion was avoided, as well as the risk of hyperthermic brain injury during rewarming (82). Convulsion, a manifestation usually related to deep hypothermia, was no longer observed, preventing longterm neurological impairment $(32,83,84)$, and myocardium rewarming between cardioplegia re-dosing was limited by the interposition of a mattress perfused with cold water.

When intermittent warm blood cardioplegia was proved to be reproducible, efficient, and safe in the adult population, we implemented this technique in pediatrics. The second step combining warm perfusion and cardioplegia started in April 2001. Warm blood cardioplegia was in fact microplegia. Warm oxygenated blood was diverted from the oxygenator or from the origin of the arterial line via a roller pump. Downstream the roller pump, the arresting agent was added via an electrical syringe pump. The ratio of blood to arresting agent was 60:1 and the cardioplegia was sucked back into the circuit. The hydric balance of microplegia was negligible, limited to the few milliliters of arresting agent (85). The arresting agent was similar to St. Thomas I, which is composed of potassium, magnesium, and procaine. The re-dosing interval was $15 \mathrm{~min}$, and we did not observe any hyperkaliemia. Our initial experience with this new protocol was satisfactory. We compared retrospectively the last 950 patients operated on with warm perfusion and cold blood cardioplegia and 1,400 patients operated on with warm perfusion and intermittent warm blood microplegia. Spontaneous resumption of sinus rhythm was $99 \%$ in the warm group versus $77 \%$ in the cold group, and intensive care length of stay was under $48 \mathrm{~h}$ in 86 versus $75 \%$. Four groups of frequent cardiopathies were selected to compare time to extubation and postoperative troponin levels: ventricular septal defect, tetralogy of Fallot, complete atrioventricular septal defect, and arterial switch operation. In each group, the results were significantly enhanced following warm surgery. Among the selected patients, mortality was comparable: 5 out of 364 (1.4\%) in the warm group versus 5 out of 255 (1.9\%) in the cold group. Following this study, we compared risk stratification in our unit to risk assessment from the Aristotle basic complexity score. Patients under $10 \mathrm{~kg}$ were included in the study, $38 \mathrm{had}$ prolonged aortic cross-clamp time defined as a cross clamping time exceeding $90 \mathrm{~min}$ (group 1), and 196 had shorter cross clamp time (group 2). In terms of mortality and prolonged hospital length of stay, our results compared favorably to the data from the Society of Thoracic Surgeons and European Association for Cardio-Thoracic Surgery database. Interestingly, blood lactate level, a biomarker of perfusion quality, was at $2.5 \mathrm{mmol}$ during bypass, peaked at $2.6 \mathrm{mmol} / \mathrm{L}$ on arrival to ICU in group 1 and reached $1.4 \mathrm{mmol} / \mathrm{L} 20 \mathrm{~h}$ later (86). This level was far lower than those associated with complicated postoperative courses described in the literature $(87,88)$.

The results obtained with warm surgery in our unit proved reproducible. The benefits of warm perfusion on immediate outcomes were confirmed through low requirement for inotropic and short time to extubation, low lactate production, adequate urine output, minimal drainage from the chest drains, short ICU and hospital stay (89). When compared to hypothermic perfusion, warm perfusion was associated with reduced oxidative stress (90). A study comparing arterial switch operation with either cold or warm surgery confirmed the benefits of warm perfusion on postoperative lactate blood levels, time to extubation and length of stay in ICU (91). Myocardial protection assessed on myocardial biopsies confirmed the superiority of warm blood microplegia, while early and late neurodevelopmental status, following warm perfusion, were equivalent to those observed during mild hypothermia (92). The absence of benefits of low temperature over warm perfusion on brain protection became ever more evident. Of note, several European units switched from cold to warm surgery, and none decided to shift back to hypothermia (89-94).

The growing experience in intermittent warm blood microplegia consolidated a significant body of evidence to support the good tolerance of warm myocardial ischemia. The issue was, as it has been for adults, to determine the maximal safe time to redosing. We progressively increased time to re-dosing from 15 to 35-40 min without any drawbacks (95-97). This slow drift was done over 10 years and was due to the frequent " 2 min" delay requested by the surgeon. In a study assessing Troponin $\mathrm{T}$ following 35-40 min re-dosing intervals, we compared 4 groups of patients: 46 patients had cardiac surgery without aortic cross clamping (group 0), 81 patients had one cardioplegia injection (group 1), 31 patients had two injections (group 2), and 7 had 3 injections (group 3). There was no significant difference in 
Troponin T levels between group 0 without myocardial ischemia and group 1 with $28.30 \pm 8.84 \mathrm{~min}$ cross clamp time. In group 2 $(65.71 \pm 9.70$ min cross clamp time), troponin was $2.17 \pm 2.29$ $\mu \mathrm{g} / \mathrm{L}$ and in group $3(114 \pm 13.71 \mathrm{~min}$ cross clamp time), the level was $3.79 \pm 3.00 \mu \mathrm{g} / \mathrm{L}$. These blood levels of troponin compare favorably to those from patients receiving cold crystalloid cardioplegia $(87,88,98)$. The main limitation of our study is the small number of long-term aortic cross clamp time.

Twenty years from the implementation of warm perfusion, and 15 years after we shifted to warm surgery, thousands of cases have been performed every year, mainly in Europe. The safety, efficiency, and advantages are widely acknowledged by surgeons who adopted this approach. We have been using the technique for all types of cardiopathies, including interruption of the aortic arch without or with transposition of the great arteries or total pulmonary anomalous venous return. During aortic arch repair, the arterial line was divided in two via a Y-type connector. The upper part of the body was perfused through the brachiocephalic artery and the lower part through the descending aorta or the femoral artery. Small femoral cannulas were specifically designed for neonates. We did not experience any of the drawbacks of femoral cannulation and immediate postoperative arterial Doppler demonstrated the permeability of the femoral artery. Many surgeons are less enthusiastic and prefer the comfort of circulatory arrest for complex cases. There is no discussion about the fact that cardiac surgery is teamwork and that the quality of surgical cure is of utmost importance. The final decision in the operating room belongs to the surgeon. However, warm surgery is not a "point of no return": in case of need, hypothermia can be instituted rapidly, especially in low-weight babies.

When coupled to warm surgery, pulsatile perfusion generates a peripheral pulse detectable with an oximeter. As expected, during pulsatile warm perfusion, pulse oximetry values were equivalent to values measured with a co-oximeter. Several commercially available monitors display not only saturation but also a numerical value known as the perfusion index, a relative assessment of the pulse strength. This index is influenced mainly by the amount of blood at the monitoring site and not by the level of oxygenation and there is some evidence that it accurately reflects peripheral perfusion $(99,100)$. We routinely monitor peripheral saturation and perfusion index, peripheral saturation and perfusion index being likely to reflect saturation and perfusion quality of end organs. Furthermore, we use peripheral saturation to adjust $\mathrm{FIO}_{2}$ at the lowest level needed to reach a saturation of $98 \%$, avoiding the potential deleterious effect of hyperoxia. In cyanotic patients, it was suggested that controlled reoxygenation decreased myocardial damage, oxidative stress, and cerebral and hepatic injury when compared to hyperoxic bypass (101). During aortic arch surgery, bilateral ear lobe sensor should display identical saturation and pulsatile index. Ear-lobe probe measures oximetry of the distal

\section{REFERENCES}

1. Bigelow WG, Callaghan JC, Hopps JA. General hypothermia for experimental intracardiac surgery; the use of electrophrenic respirations, an artificial pacemaker for cardiac standstill and radio-frequency rewarming in general hypothermia. Ann Surg (1950) 132:531-9. doi:10.1097/00000658-195009000-00018 part of the external carotid artery and, in young patients, is likely to be a strong predictor of brain blood saturation. This simple tool could be a valuable alternative to monitoring of regional cerebral oxygenation via near-infrared spectroscopy. Studies comparing the two techniques are underway.

Beside the medical advantages, warm perfusion and intermittent warm blood microplegia are also cost-effective. The microplegia circuit is simple and therefore inexpensive and the arresting agent costs but a few euros. Furthermore, the negligible hydric balance of microplegia is a positive factor for blood conservation and contributes to reduce blood transfusion. For all these reasons, warm surgery was implemented by European teams in many humanitarian surgery missions. During missions, warm surgery is the perfect answer to the need for inexpensive and simple procedure, short time on bypass, and short intensive care length of stay, allowing more cases to be performed.

The main objection raised by opponents to warm surgery is the absence of safety margin in case of incident, requiring circulatory arrest lasting more than a few minutes. This is true, and if a surgeon experienced such incident during cold perfusion, he would probably better not implement warm surgery. However, after decades of application and tens of thousands of cases performed in numerous centers, we can confirm that the accidental risk is not a valuable reason to be afraid of warm surgery.

It is always challenging to choose a way opposite to the "gold standard" and the implementation of warm pediatric cardiac surgery was initially done against the opinion of the medical community. Nowadays, the results of pediatric cardiac surgery are so good that the number of patients needed to demonstrate the benefit of warm perfusion on mortality makes such a single center study utopian. Furthermore, cardiopulmonary bypass is only one element in the management of a patient. Cardiac surgery is a teamwork, the results of which depend on everyone involved in diagnosis, surgery, and intensive care including all the doctors, technician, and nurses from the medical staff. However, when a technique is simple, reproducible, safe, efficient, and cost-effective, and when no one changed his mind after choosing to implement it, it suggests that the approach makes sense. We can hardly imagine that full flow warm oxygenated blood brain perfusion could be worse than circulatory arrest or deep hypothermic regional cerebral perfusion. It is difficult to conceive that the good results observed in short-term outcomes on myocardial and brain functions could worsen over time, and we do hope that longitudinal studies will, in a next future, demonstrate the quality of long-term results of warm surgery.

\section{AUTHOR CONTRIBUTIONS}

The author confirms being the sole contributor of this work and approved it for publication.

2. Bigelow WG, Lindsay WK, Greenwood WF. Hypothermia; its possible role in cardiac surgery: an investigation of factors governing survival in dogs at low body temperatures. Ann Surg (1950) 132:849-66. doi:10.1097/00000658-195011000-00001

3. Karaskov AM, Litasova EE, Vlasov YA. A documentary on the life and work of Eugenij Nikolaevich Meshalkin. Circ Pathol Cardiac Surg (1999) 1:4-11. 
4. McGoon DC, Moffitt EA, Theye RA, Kirklin JW. Physiologic studies during high flow normothermic whole body perfusion. J Thorac Cardiovasc Surg (1960) 39:275-87.

5. MoffittEA, Sessler AD, Molnar GD, McGoon DC. Normothermia versushypothermiafor whole-body perfusion:effectson myocardialand bodymetabolism. Anesth Analg (1971) 50:505-16. doi:10.1213/00000539-197107000-00004

6. Sealy WC, Brown IW Jr, Young WG, Smith WW, Lesage AM. Hypothermia and extracorporeal circulation for open heart surgery: its simplification with a heat exchanger for rapid cooling and rewarming. Ann Surg (1959) 150:627-39. doi:10.1097/00000658-195910000-00008

7. Shumway NE, Lower RR, Stofer RC. Selective hypothermia of the heart in anoxic cardiac arrest. Surg Gynecol Obstet (1959) 109:750-4.

8. Bretschneider HJ. Survival time and recuperative time of the heart in normothermia and hypothermia. Verh Dtsch Ges Kreislaufforsch (1964) 30:11-34.

9. Bernhard WF, Gross RE. The rationale of hypothermic cardioplegia in the management of congenital anomalies affecting the aortic valve, coronary arteries and proximal aortic arch. Ann Surg (1962) 156:161-72. doi:10.1097/00000658-196208000-00001

10. Kirklin JW, Wallace RB, McGoon DC, DuShane JW. Early and late results after intracardiac repair of Tetralogy of Fallot. 5-year review of 337 patients. Ann Surg (1965) 162:578-89. doi:10.1097/00000658-196510000-00004

11. Bretschneider HJ, Hübner G, Knoll D, Lohr B, Nordbeck H, Spieckermann PG. Myocardial resistance and tolerance to ischemia: physiological and biochemical basis. J Cardiovasc Surg (Torino) (1975) 16:241-60.

12. Barnard CN, Schrire V. The surgical treatment of acquired aneurysm of the throracic aorta. Thorax (1963) 18:101-15. doi:10.1136/thx.18.2.101

13. Griepp RB, Stinson EB, Hollingsworth JF, Buehler D. Prosthetic replacement of the aortic arch. J Thorac Cardiovasc Surg (1975) 70:1051-63.

14. Barratt-Boyes BG, Neutze JM. Primary repair of tetralogy of Fallot in infancy using profound hypothermia with circulatory arrest and limited cardiopulmonary bypass: a comparison with conventional two stage management. Ann Surg (1973) 178:406-11. doi:10.1097/00000658-197310000-00003

15. Wade OL, Bishop JM. Cardiac Output and Regional Blood Flow. Oxford: Blackwell Scientific Publications, Ltd (1962).

16. Whittaker CL, Grist GE. The theoretical prediction of safe deep hypothermic circulatory arrest (DHCA) time using estimated tissue oxygen loading. Prog Pediatr Cardiol (2008) 24:117-22. doi:10.1016/j.ppedcard.2007.10.007

17. Kirklin JW, Barratt-Boyes BG. Hypothermia, Circulatory Arrest, and Cardiopulmonary Bypass. Cardiac Surgery. Second ed. New York: Churchill Livingstone (1993). p. 61-127.

18. McCullough JN, Zhang N, Reich DL, Juvonen TS, Klein JJ, Spielvogel D. Cerebral metabolic suppression during hypothermic circulatory arrest in humans. Ann Thorac Surg (1999) 67:1895-9. doi:10.1016/ S0003-4975(99)00441-5

19. Coselli JS, Crawford ES, Beall AC Jr, Mizrahi EM, Hess KR, Patel VM. Determination of brain temperatures for safe circulatory arrest during cardiovascular operation. Ann Thorac Surg (1988) 45:638-42. doi:10.1016/ S0003-4975(10)64766-2

20. Stephan H, Weyland A, Kazmaier S, Henze T, Menck S, Sonntag H. Acid-base management during hypothermic cardiopulmonary bypass does not affect cerebral metabolism but does affect blood flow and neurological outcome. Br J Anaesth (1992) 69:51-7. doi:10.1093/bja/69.1.51

21. Patel RL, Turtle MR, Chambers DJ, James DN, Newman S, Venn GE. Alpha-stat acid-base regulation during cardiopulmonary bypass improves neuropsychologic outcome in patients undergoing coronary artery bypass grafting. J Thorac Cardiovasc Surg (1996) 111:1267-79. doi:10.1016/ S0022-5223(96)70230-1

22. Aoki M, Nomura F, Stromski ME, Tsuji MK, Fackler JC, Hickey PR, et al. Effects of $\mathrm{pH}$ on brain energetics after hypothermic circulatory arrest. Ann Thorac Surg (1993) 55:1093-103. doi:10.1016/0003-4975(93)90014-9

23. Skaryak LA, Chai PJ, Kern FH, Greeley WJ, Ungerleider RM. Blood gas management and degree of cooling: effects on cerebral metabolism before and after circulatory arrest. J Thorac Cardiovasc Surg (1995) 110:1649-57. doi:10.1016/S0022-5223(95)70026-9

24. Kurth CD, O’Rourke MM, O'Hara IB. Comparison of pH-stat and alpha-stat cardiopulmonary bypass on cerebral oxygenation and blood flow in relation to hypothermic circulatory arrest in piglets. Anesthesiology (1998) 89:110-8. doi:10.1097/00000542-199807000-00018
25. du Plessis AJ, Jonas RA, Wypij D, Hickey PR, Riviello J, Wessel DL, et al. Perioperative effects of alpha-stat versus $\mathrm{pH}$-stat strategies for deep hypothermic cardiopulmonary bypass in infants. J Thorac Cardiovasc Surg (1997) 114:991-1000; discussion 1000-1. doi:10.1016/S0022-5223(97)70013-8

26. Abdul Aziz KA, Meduoye A. Is pH-stat or alpha-stat the best technique to follow in patients undergoing deep hypothermic circulatory arrest? Interact Cardiovasc Thorac Surg (2010) 10:271-82. doi:10.1510/icvts.2009.214130

27. Medlock MD, Cruse RS, Winek SJ, Geiss DM, Horndasch RL, Schultz DL, et al. A 10-year experience with postpump chorea. Ann Neurol (1993) 34:820-6. doi:10.1002/ana.410340611

28. Wong PC, Barlow CF, Hickey PR, Jonas RA, Castaneda AR, Farrell DM, et al. Factors associated with choreoathetosis after cardiopulmonary bypass in children with congenital heart disease. Circulation (1992) 86(Suppl):II118-26.

29. Ehyai A, Fenichel GM, Bender HW Jr. Incidence and prognosis of seizures in infants after cardiac surgery with profound hypothermia and circulatory arrest. JAMA (1984) 252:3165-7. doi:10.1001/jama.1984.03350220071035

30. Rappaport LA, Wypij D, Bellinger DC, Helmers SL, Holmes GL, Barnes PD, et al. Relation of seizures after cardiac surgery in early infancy to neurodevelopmental outcome. Boston Circulatory Arrest Study Group. Circulation (1998) 97:773-9. doi:10.1161/01.CIR.97.8.773

31. Helmers SL, Wypij D, Constantinou JE, Newburger JW, Hickey PR, Carrazana EJ, et al. Perioperative electroencephalographic seizures in infants undergoing repair of complex congenital cardiac defects. Electroencephalogr Clin Neurophysiol (1997) 102:27-36. doi:10.1016/S0013-4694(96)95079-8

32. Clancy RR, McGaurn SA, Wernovsky G, Gaynor JW, Spray TL, Norwood WI, et al. Risk of seizures in survivors of newborn heart surgery using deep hypothermic circulatory arrest. Pediatrics (2003) 111:592-601. doi:10.1542/ peds.111.3.592

33. Guilmet D, Roux PM, Bachet J, Goudot B, Tawil N, Diaz F. A new technic of cerebral protection. Surgery of the aortic arch. Presse Med (1986) 15:1096-8.

34. Kazui T. Update in surgical management of aneurysms of the thoracic aorta. Rinsho Kyobu Geka (1986) 6:7-15.

35. Bachet J, Guilmet D, Goudot B, Dreyfus GD, Delentdecker P, Brodaty D, et al. Antegrade cerebral perfusion with cold blood: a 13-year experience. Ann Thorac Surg (1999) 67:1874-8. doi:10.1016/S0003-4975(99)00411-7

36. Pigula FA, Nemoto EM, Griffith BP, Siewers RD. Regional low-flow perfusion provides cerebral circulatory support during neonatal aortic arch reconstruction. J Thorac Cardiovasc Surg (2000) 119:331-9. doi:10.1016/ S0022-5223(00)70189-9

37. Asou T, Kado H, Imoto Y, Shiokawa Y, Tominaga R, Kawachi Y, et al. Selective cerebral perfusion technique during aortic arch repair in neonates. Ann Thorac Surg (1996) 61:1546-8. doi:10.1016/0003-4975(96)80002-S

38. Goldberg CS, Bove EL, Devaney EJ, Mollen E, Schwartz E, Tindall S, et al. A randomized clinical trial of regional cerebral perfusion versus deep hypothermic circulatory arrest: outcomes for infants with functional single ventricle. J Thorac Cardiovasc Surg (2007) 133:880-7. doi:10.1016/j.jtcvs.2006.11.029

39. Hoffman GM, Stuth EA, Jaquiss RD, Vanderwal PL, Staudt SR, Troshynski $\mathrm{TJ}$, et al. Changes in cerebral and somatic oxygenation during stage 1 palliation of hypoplastic left heart syndrome using continuous regional cerebral perfusion. J Thorac Cardiovasc Surg (2004) 127:223-33. doi:10.1016/j. jtcvs.2003.08.021

40. Sistino JJ, Atz AM, Ellis C Jr, Simpson KN, Ikonomidis JS, Bradley SM. Association between method of cerebral protection during neonatal aortic arch surgery and attention deficit/hyperactivity disorder. Ann Thorac Surg (2015) 100:663-70. doi:10.1016/j.athoracsur.2015.04.119

41. Mahan VL, Ilangovan S, Cuison R, Patil J, Dockter S, Rizzo V, et al. Does antegrade cerebral perfusion protect the brain during deep hypothermic circulatory arrest? J Pediatr Surg (2005) 40:510-5. doi:10.1016/j. jpedsurg.2004.11.043

42. Dexter F, Hindman BJ. Theoretical analysis of cerebral venous blood hemoglobin oxygen saturation as an index of cerebral oxygenation during hypothermic cardiopulmonary bypass. A counterproposal to the "luxury perfusion" hypothesis. Anesthesiology (1995) 83:405-12. doi:10.1097/00000542-199508000-00021

43. Polito A, Ricci Z, Di Chiara L, Giorni C, Iacoella C, Sanders SP. Cerebral blood flow during cardiopulmonary bypass in pediatric cardiac surgery: the role of transcranial Doppler - a systematic review of the literature. Cardiovasc Ultrasound (2006) 4:47-58. doi:10.1186/1476-7120-4-47 
44. Archie JP, Kirklin JW. Effect of hypothermic perfusion and myocardial oxygen consumption and coronary resistance. Surg Forum (1973) 24:186-8.

45. Buckberg GD, Brazier JR, Nelson RL, Goldstein SM, McConnell DH, Cooper N. Studies of the effects of hypothermia on regional myocardial blood flow and metabolism during cardiopulmonary bypass. I. The adequately perfused beating, fibrillating, and arrested heart. J Thorac Cardiovasc Surg (1977) 73:87-94.

46. Bernhard WF, Schwarz HF, Mallick NP. Elective hypothermic cardiac arrest in normothermic animals. Ann Surg (1961) 153:43-51. doi:10.1097/00000658-196101000-00005

47. Kanter GS. Renal clearance of sodium and potassium in hypothermia. Can J Biochem Physiol (1962) 40:113-22. doi:10.1139/o62-015

48. Morales P, Carbery W, Morello A, Morales G. Alterations in renal function during hypothermia in man. Ann Surg (1957) 145:488-99. doi:10.1097/00000658-195704000-00005

49. Moyer JH. The effect of hypothermia on renal function and renal damage from ischemia. Ann N Y Acad Sci (1959) 80:424-34. doi:10.1111/j.1749-6632.1959. tb49220.x

50. Sinclair DG, Haslam PL, Quinlan GJ, Pepper JR, Evans TW. The effect of cardiopulmonary bypass on intestinal and pulmonary endothelial permeability. Chest (1995) 108:718-24. doi:10.1378/chest.108.3.718

51. Ohri SK, Bjarnason I, Pathi V, Somasundaram S, Bowles CT, Keogh BE, et al. Cardiopulmonary bypass impairs small intestinal transport and increases gut permeability. Ann Thorac Surg (1993) 55:1080-6. doi:10.1016/0003-4975(93)90011-6

52. Deal CW, Warden JC, Monk I. Effect of hypothermia on lung compliance. Thorax (1970) 25:105-9. doi:10.1136/thx.25.1.105

53. Collins HA, Stahlman M, Scott HW Jr. The occurrence of subcutaneous fat necrosis in an infant following induced hypothermia used as an adjuvant in cardiac surgery. Ann Surg (1953) 138:880-5. doi:10.1097/00000658-195312000-00010

54. Chuang SD, Chiu HC, Chang CC. Subcutaneous fat necrosis of the newborn complicating hypothermic cardiac surgery. Br J Dermatol (1995) 132:805-10. doi:10.1111/j.1365-2133.1995.tb00731.x

55. Baum D, Dillard DH, Porte D Jr. Inhibition of insulin release in infants undergoing deep hypothermic cardiovascular surgery. N Engl J Med (1968) 279:1309-14. doi:10.1056/NEJM196812122792404

56. Valeri CR, Feingold H, Cassidy G, Ragno G, Khuri S, Altschule MD. Hypothermia-induced reversible platelet dysfunction. Ann Surg (1987) 205:175-81. doi:10.1097/00000658-198702000-00012

57. Beilin B, Shavit Y, Razumovsky J, Wolloch Y, Zeidel A, Bessler H. Effects of mild perioperative hypothermia on cellular immune responses. Anesthesiology (1998) 89:1133-40. doi:10.1097/00000542-199811000-00013

58. Kofstad J. Blood gases and hypothermia: some theoretical and practical considerations. Scand JClin Lab Invest Suppl (1996) 224:21-6. doi:10.3109/00365519609088622

59. Ehrlich MP, McCullough JN, Zhang N, Weisz DJ, Juvonen T, Bodian CA, et al. Effect of hypothermia on cerebral blood flow and metabolism in the pig. Ann Thorac Surg (2002) 73:191-7. doi:10.1016/S0003-4975(01)03273-8

60. Okamura T, Ishibashi N, Kumar TS, Zurakowski D, Iwata Y, Lidov HG, et al. Hypothermic circulatory arrest increases permeability of the blood brain barrier in watershed areas. Ann Thorac Surg (2010) 90:2001-8. doi:10.1016/j. athoracsur.2010.06.118

61. Snookes SH, Gunn JK, Eldridge BJ, Donath SM, Hunt RW, Galea MP, et al. A systematic review of motor and cognitive outcomes after early surgery for congenital heart disease. Pediatrics (2010) 125:e818-27. doi:10.1542/ peds.2009-1959

62. McAnally HB, Cutter GR, Ruttenber AJ, Clarke D, Todd JK. Hypothermia as a risk factor for pediatric cardiothoracic surgical site infection. Pediatr Infect Dis J (2001) 20:459-62. doi:10.1097/00006454-200104000-00023

63. Salvin JW, Scheurer MA, Laussen PC, Wypij D, Polito A, Bacha EA, et al. Blood transfusion after pediatric cardiac surgery is associated with prolonged hospital stay. Ann Thorac Surg (2011) 91:204-10. doi:10.1016/j. athoracsur.2010.07.037

64. Iyengar A, Scipione CN, Sheth P, Ohye RG, Riegger L, Bove EL, et al. Association of complications with blood transfusions in pediatric cardiac surgery patients. Ann Thorac Surg (2013) 96:910-6. doi:10.1016/j. athoracsur.2013.05.003
65. Guyton AC. Textbook of Medical Physiology. Seventh ed. Philadelphia: WB Saunders Company (1986). 335 p.

66. Allen BS, Ko Y, Buckberg GD, Tan Z. Studies of isolated global brain ischaemia: II. Controlled reperfusion provides complete neurologic recovery following $30 \mathrm{~min}$ of warm ischaemia - the importance of perfusion pressure. Eur J Cardiothorac Surg (2012) 41:1147-54. doi:10.1093/ejcts/ezr317

67. Huang SC, Wu ET, Chen YS, Chang CI, Chiu IS, Wang SS, et al. Extracorporeal membrane oxygenation rescue for cardiopulmonary resuscitation in pediatric patients. Crit Care Med (2008) 36:1607-13. doi:10.1097/ CCM.0b013e318170b82b

68. Utley JR. Pathophysiology and Techniques of Cardiopulmonary Bypass. (Vol. II). Baltimore: Williams \& Wilkins (1983). 37 p.

69. Lichtenstein SV, el Dalati H, Panos A, Slutsky AS. Long cross-clamp time with warm heart surgery. Lancet (1989) 1(8652):1443. doi:10.1016/ S0140-6736(89)90140-2

70. The Warm Heart Investigators. Randomised trial of normothermic versus hypothermic coronary bypass surgery. Lancet (1994) 343(8897):559-63 doi:10.1016/S0140-6736(94)91519-9

71. Fremes SE, Tamariz MG, Abramov D, Christakis GT, Sever JY, Sykora K, et al. Late results of the Warm Heart Trial: the influence of nonfatal cardiac events on late survival. Circulation (2000) 102(Suppl 3):III339-45. doi:10.1161/01. CIR.102.suppl_3.III-339

72. Calafiore AM, Teodori G, Di Giammarco G, Bosco G, Mezzetti A, Lapenna D, et al. Intermittent antegrade cardioplegia: warm blood vs cold crystalloid. A clinical study. J Cardiovasc Surg (Torino) (1994) 35(Suppl 1):179-84.

73. Calafiore AM, Teodori G, Mezzetti A, Bosco G, Verna AM, Di Giammarco G, et al. Intermittent antegrade warm blood cardioplegia. Ann Thorac Surg (1995) 59:398-402. doi:10.1016/0003-4975(94)00843-V

74. Franke UF, Korsch S, Wittwer T, Albes JM, Wippermann J, Kaluza M, et al. Intermittent antegrade warm myocardial protection compared to intermittent cold blood cardioplegia in elective coronary surgery - do we have to change? Eur J Cardiothorac Surg (2003) 23:341-6. doi:10.1016/ s1010-7940(02)00828-x

75. Lichtenstein SV, Naylor CD, Feindel CM, Sykora K, Abel JG, Slutsky AS, et al. Intermittent warm blood cardioplegia. Warm Heart Investigators. Circulation (1995) 92(Suppl):II341-6. doi:10.1161/01.CIR.92.9.341

76. Mallidi HR, Sever J, Tamariz M, Singh S, Hanayama N, Christakis GT, et al. The short-term and long-term effects of warm or tepid cardioplegia. J Thorac Cardiovasc Surg (2003) 125:711-20. doi:10.1067/mtc.2003.105

77. Jacquet LM, Noirhomme PH, Van Dyck MJ, El Khoury GA, Matta AJ, Goenen MJ, et al. Randomized trial of intermittent antegrade warm blood versus cold crystalloid cardioplegia. Ann Thorac Surg (1999) 67:471-7. doi:10.1016/S0003-4975(98)01198-9

78. Christakis GT, Abel JG, Lichtenstein SV. Neurological outcomes and cardiopulmonary temperature: a clinical review. JCard Surg (1995) 10(Suppl):475-80. doi:10.1111/j.1540-8191.1995.tb00680.x

79. MenaschéP,PeynetJ,TouchotB,AzizM,HaydarS,PerezG, etal.Normothermic cardioplegia: is aortic cross-clamping still synonymous with myocardial ischemia? Ann Thorac Surg (1992) 54:472-7. doi:10.1016/0003-4975(92)90437-9

80. Minatoya K, Okabayashi H, Shimada I, Tanabe A, Nishina T, Nandate K, et al. Intermittent antegrade warm blood cardioplegia for CABG: extended interval of cardioplegia. Ann Thorac Surg (2000) 69:74-6. doi:10.1016/ S0003-4975(99)01384-3

81. Ghazy T, Allham O, Ouda A, Kappert U, Matschke K. Is repeated administration of blood-cardioplegia really necessary? Interact Cardiovasc Thorac Surg (2009) 8:517-21. doi:10.1510/icvts.2008.192757

82. Bissonnette B, Holtby HM, Davis AJ, Pua H, Gilder FJ, Black M. Cerebral hyperthermia in children after cardiopulmonary bypass. Anesthesiology (2000) 93:611-8. doi:10.1097/00000542-200009000-00008

83. Newburger JW, Jonas RA, Wernovsky G, Wypij D, Hickey PR, Kuban KC, et al. A comparison of the perioperative neurologic effects of hypothermic circulatory arrest versus low-flow cardiopulmonary bypass in infant heart surgery. N Engl J Med (1993) 329:1057-64. doi:10.1056/NEJM199310073291501

84. Bellinger DC, Wypij D, Rivkin MJ, DeMaso DR, Robertson RC Jr, DunbarMasterson C, et al. Adolescents with d-transposition of the great arteries corrected with the arterial switch procedure: neuropsychological assessment and structural brain imaging. Circulation (2011) 124:1361-9. doi:10.1161/ CIRCULATIONAHA.111.026963 
85. Durandy Y, Hulin S. Intermittent warm blood cardioplegia in the surgical treatment of congenital heart disease: clinical experience with 1400 cases. J Thorac Cardiovasc Surg (2007) 133:241-6. doi:10.1016/j.jtcvs. 2006.10.004

86. Durandy Y, Younes M, Mahut B. Pediatric warm open heart surgery and prolonged cross-clamp time. Ann Thorac Surg (2008) 86:1941-7. doi:10.1016/j. athoracsur.2008.08.004

87. Taggart DP, Hadjinikolas L, Wong K, Yap J, Hooper J, Kemp M, et al. Vulnerability of paediatric myocardium to cardiac surgery. Heart (1996) 76:214-7. doi:10.1136/hrt.76.3.214

88. Lipshultz SE, Rifai N, Sallan SE, Lipsitz SR, Dalton V, Sacks DB, et al. Predictive value of cardiac troponin $\mathrm{T}$ in pediatric patients at risk for myocardial injury. Circulation (1997) 96:2641-8. doi:10.1161/01.CIR.96.8.2641

89. Shamsuddin AM, Nikman AM, Ali S, Zain MR, Wong AR, Corno AF. Normothermia for pediatric and congenital heart surgery: an expanded horizon. Front Pediatr (2015) 3:23. doi:10.3389/fped.2015.00023

90. Caputo M, Bays S, Rogers CA, Pawade A, Parry AJ, Suleiman S, et al. Randomized comparison between normothermic and hypothermic cardiopulmonary bypass in pediatric open-heart surgery. Ann Thorac Surg (2005) 80:982-8. doi:10.1016/j.athoracsur.2005.03.062

91. Pouard P, Mauriat P, EkF, Haydar A, Gioanni S, Laquay N, et al. Normothermic cardiopulmonary bypass and myocardial cardioplegic protection for neonatal arterial switch operation. Eur J Cardiothorac Surg (2006) 30:695-9. doi:10.1016/j.ejcts.2006.07.032

92. Poncelet AJ, van Steenberghe M, Moniotte S, Detaille T, Beauloye C, Bertrand L, et al. Cardiac and neurological assessment of normothermia/ warm blood cardioplegia vs hypothermia/cold crystalloid cardioplegia in pediatric cardiac surgery: insight from a prospective randomized trial. Eur J Cardiothorac Surg (2011) 40:1384-90. doi:10.1016/j.ejcts.2011.03.047

93. Corno AF, von Segesser LK. Is hypothermia necessary in pediatric cardiac surgery? Eur J Cardiothorac Surg (1999) 15:110-1. doi:10.1016/ S1010-7940(98)00291-7

94. Durandy Y. Warm pediatric cardiac surgery: European experience. Asian Cardiovasc Thorac Ann (2010) 18:386-95. doi:10.1177/0218492310376675
95. Durandy Y, Rubatti M. Warm blood microplegia redosing interval in pediatric surgery. Ann Thorac Surg (2013) 96:2285-6. doi:10.1016/j. athoracsur.2013.06.076

96. Rubatti M, Durandy Y. Prolonged warm ischemia for transfusion-free arterial switch and ventricular septal defect surgery in a $4.5-\mathrm{Kg}$ baby. Perfusion (2012) 27:230-4. doi:10.1177/0267659112437775

97. Durandy YD. Is there a rationale for short cardioplegia re-dosing intervals? World J Cardiol (2015) 7:658-64. doi:10.4330/wjc.v7.i10.658

98. Mildh LH, Pettilä V, Sairanen HI, Rautiainen PH. Cardiac troponin T levels for risk stratification in pediatric open heart surgery. Ann Thorac Surg (2006) 82:1643-8. doi:10.1016/j.athoracsur.2006.05.014

99. De Felice C, Latini G, Vacca P, Kopotic RJ. The pulse oximeter perfusion index as a predictor for high illness severity in neonates. Eur J Pediatr (2002) 161:561-2. doi:10.1007/s00431-002-1042-5

100. Hakan N, Dilli D, Zenciroglu A, Aydin M, Okumus N. Reference values of perfusion indices in hemodynamically stable newborns during the early neonatal period. Eur J Pediatr (2014) 173:597-602. doi:10.1007/ s00431-013-2224-z

101. Caputo M, Mokhtari A, Miceli A, Ghorbel MT, Angelini GD, Parry AJ, et al. Controlled reoxygenation during cardiopulmonary bypass decreases markers of organ damage, inflammation, and oxidative stress in single-ventricle patients undergoing pediatric heart surgery. J Thorac Cardiovasc Surg (2014) 148:792-801. doi:10.1016/j.jtcvs.2014.06.001

Conflict of Interest Statement: The author declares that the research was conducted in the absence of any commercial or financial relationships that could be construed as a potential conflict of interest.

Copyright (C) 2016 Durandy. This is an open-access article distributed under the terms of the Creative Commons Attribution License (CC BY). The use, distribution or reproduction in other forums is permitted, provided the original author(s) or licensor are credited and that the original publication in this journal is cited, in accordance with accepted academic practice. No use, distribution or reproduction is permitted which does not comply with these terms. 